\title{
SINTERABILIDADE DE PÓS DE PRECURSOR VITROCERÂMICO DO SISTEMA LZSA TRATADOS POR TROCA IÔNICA
}

\section{Oscar Rubem Klegues Montedo*}

Unidade Acadêmica de Ciências, Engenharias e Tecnologia, Universidade do Extremo Sul Catarinense, Av. Universitária, 1105, 88806-000 Criciúma - SC, Brasil

Patrícia Ronsani e Antonio Pedro Novaes de Oliveira

Departamento de Engenharia Mecânica, Universidade Federal de Santa Catarina, 88040-970 Florianópolis - SC, Brasil

Recebido em 25/4/11; aceito em 2/11/11; publicado na web em 23/1/12

\begin{abstract}
SINTERABILITY OF POWDERS OF PARENT GLASSCERAMIC BELONGING TO THE LZSA SYSTEM TREATED BY ION EXCHANGE. Ion exchange method was employed by means of surface modification of the glass powders of $\mathrm{LZSA}_{\left(\mathrm{Li}_{2} \mathrm{O}-\mathrm{ZrO}{ }_{2}-\right.}$ $\mathrm{SiO}_{2}-\mathrm{Al}_{2} \mathrm{O}_{3}$ ) system submitted to a $70 \mathrm{wt} \% \mathrm{NaNO}_{3} / 30 \mathrm{wt} \% \mathrm{NaSO}_{4}$ bath salt followed by a heat treatment. Chemical analysis by X-ray fluorescence was used to evaluate the efficiency of ion exchange, while optical dilatometry was employed to evaluate sintering of compacts. Evaluation of the structure of sintered bodies was made by scanning electron microscopy. Substitution of $\mathrm{Li}^{+}$ions by $\mathrm{Na}^{+}$ ions on the surface of powders during heat treatments of 450 and $600{ }^{\circ} \mathrm{C}$ for $2-10 \mathrm{~h}$ promoted an increase in densification of the sintered bodies.
\end{abstract}

Keywords: glassceramics; ion exchange; sintering.

\section{INTRODUÇÃO}

Muitos esforços têm sido dispensados nas últimas décadas para se melhorar o comportamento mecânico, térmico e químico de materiais cerâmicos, como o estudo de novas composições, o emprego de partículas de reforço formando compósitos de matriz cerâmica, ${ }^{1}$ o desenvolvimento de novas tecnologias como a compactação a quente (hot pressing - HP e hot isostatic pressing - HIP) ${ }^{2}$ e, mais recentemente, a produção de materiais cerâmicos multicamadas ${ }^{3}$ e o emprego de nanopartículas, dentre outros. Dentre estes, os materiais vitrocerâmicos têm sido largamente estudados nos últimos 60 anos, representando uma alternativa técnica e tecnológica de interesse para várias aplicações, tais como lentes de telescópio, cooktops e resistores elétricos. Técnica porque suas propriedades podem ser desenvolvidas a temperaturas inferiores àquelas de muitos materiais cerâmicos convencionais, como alumina e zircônia, e tecnológica porque se podem empregar as mesmas formas de processamento existentes na tecnologia do pó ou do vidro.

Originalmente, os materiais vitrocerâmicos foram desenvolvidos a partir da fusão de óxidos, conformação do líquido viscoso e resfriamento controlado ou tratamento térmico posterior. Por outro lado, nos últimos 25 anos, ${ }^{4}$ a tecnologia do pó vem sendo empregada para a obtenção de materiais vitrocerâmicos. Neste caso, o pó do precursor vitrocerâmico (vidro) é compactado na forma desejada e, então, submetido a um tratamento térmico, compreendido pelas etapas de sinterização e cristalização, que resulta na consolidação e definição das propriedades do compacto de pós. É sabido que, no caso de pós de vidro, a sinterização ocorre antes da cristalização. ${ }^{5,6}$ Entretanto, neste caso, o processo de nucleação e crescimento cristalino dificulta a obtenção de materiais mais densos. De fato, Montedo et al. ${ }^{7}$ demonstraram que o processo de cristalização dificultou a obtenção de um material mais denso, devido à redução da taxa de retração térmica durante o tratamento térmico contínuo de uma composição vitrocerâmica do sistema $\mathrm{LZSA}\left(\mathrm{Li}_{2} \mathrm{O}-\mathrm{ZrO}_{2}-\mathrm{SiO}_{2}-\mathrm{Al}_{2} \mathrm{O}_{3}\right)$.

A porosidade residual, todavia, pode ser uma limitação prejudicial

*e-mail: oscar.rkm@gmail.com em certas aplicações. Sua redução pode ser obtida mediante tratamento térmico adequado de sinterização e cristalização. Por outro lado, ajustes ou modificações das características e propriedades do pó do precursor vitrocerâmico também podem propiciar maior densificação do material. Tratamentos químicos podem ser uma alternativa para modificar a superfície das partículas de pós de vidros e, assim, retardar o processo de nucleação e cristalização, aumentando o intervalo de sinterização para temperaturas mais elevadas. Alguns exemplos de tratamentos superficiais que melhoram a sinterabilidade de pós de vidro são: ataque por soluções de $\mathrm{NaOH}$; recobrimento com um filme com composição química diferente daquela do material de base e, troca iônica. ${ }^{4}$

A troca iônica pode ser entendida como um processo onde o vidro original é imerso dentro de um sal alcalino fundido a uma temperatura abaixo da transição vítrea $\left(\mathrm{T}_{\mathrm{g}}\right){ }^{8}$ Durante o tempo de imersão, os íons alcalinos do vidro próximos à superfície são trocados por aqueles do sal fundido. Esta substituição iônica ocorre em um processo termicamente ativado de interdifusão, em razão do raio iônico do íon penetrante ser maior do que o do íon que está sendo substituído no vidro.

Esta tecnologia tem sido empregada com êxito para obtenção de estruturas fotônicas ativas a partir de vidros de silicato dopados com lítio, este último substituído superficialmente por íons érbio $\left(\mathrm{Er}^{+3}\right)$, para aplicação na área de telecomunicações; ${ }^{9}$ na obtenção de vidro nuclear não radioativo com o objetivo de armazenar resíduos nucleares de forma adequada; ${ }^{10}$ na produção de vidros bioativos contendo íons prata $\left(\mathrm{Ag}^{+1}\right)$ inseridos na superfície do vidro calco-sódico para a obtenção de materiais antimicrobianos $;{ }^{11}$ no aumento da resistência mecânica de vidros de silicato por meio da troca de íons alcalinos contidos em um sal fundido ${ }^{8}$ dentre outras aplicações.

No caso de vitrocerâmicos, a técnica de troca iônica é empregada para se obter materiais mais densos. Isto permite produzir um significativo aumento relativo do volume molar da superfície da partícula, em comparação com seu interior, densificando o material. ${ }^{12}$ Essa substituição produz um rompimento na rede estrutural, quebrando as ligações originais e formando novas ligações. Isto modifica as cinéticas de sinterização e de cristalização, provocando 
a densificação do vidro. O aumento da cinética de sinterização, em particular, está relacionado à formação de uma auréola no perímetro de toda a superfície da partícula de vidro, mais rica do cátion menor e, portanto, menos viscosa, a uma mesma temperatura, em confronto com o pó não tratado.

Para vidros contendo lítio, como os do sistema LZSA, nitratos de sódio ou potássio são os sais mais empregados para troca iônica, por exemplo, para a têmpera química de vidros.

A troca iônica se diferencia das outras técnicas por ser realizada em temperaturas inferiores à temperatura de transição vítrea, já que em temperaturas maiores os novos íons se acomodariam sem dificuldade e não produziriam rompimentos e tensões. ${ }^{13}$

Assim, o objetivo deste trabalho foi investigar o aumento da densificação de pós de precursor vitrocerâmico do sistema LZSA, com superfícies modificadas por meio da troca iônica.

\section{PARTE EXPERIMENTAL}

Uma frita vitrocerâmica de composição $18,8 \mathrm{Li}_{2} \mathrm{O} \cdot 7,4 \mathrm{ZrO}_{2}$ • $64,3 \mathrm{SiO}_{2} \cdot 9,5 \mathrm{Al}_{2} \mathrm{O}_{3}$ foi preparada a partir de quantidades apropriadas de $\mathrm{Li}_{2} \mathrm{CO}_{3}, \mathrm{ZrSiO}_{4}, \mathrm{SiO}_{2}$ e espodumênio ( $\left.\mathrm{LiAl}\left[\mathrm{Si}_{2} \mathrm{O}_{6}\right]\right)$ como matériasprimas (Colorminas Colorifício e Mineração, Criciúma, Brasil). Esta frita foi obtida por fusão $\left(1500{ }^{\circ} \mathrm{C} / 7 \mathrm{~h}\right)$ em forno a gás, com refratários de mulita, e pré-moída a seco em moinho rápido de laboratório (Gabrielli, Itália; $900 \mathrm{rpm}$ ) com bolas de alumina por cerca de $10 \mathrm{~min}$. $\mathrm{O}$ pó obtido foi passado em malha 150 mesh $(106 \mu \mathrm{m})$. A seguir, este pó foi moído a úmido em moinho cilíndrico durante $30 \mathrm{~min}$ e, então, submetido à secagem em uma estufa de laboratório (Ceramic Instruments, Sassuolo, Itália; $110 \pm 5^{\circ} \mathrm{C}, 24$ h). O tamanho médio de partículas foi determinado em um analisador de tamanho de partículas de varredura a laser (Cilas 1064L, Orleans, França) e era de 15,66 $\mu \mathrm{m}$.

Uma balança com resolução de $0,1 \mathrm{~g}$ foi empregada para a pesagem das misturas contendo sais.

Misturas contendo $33 \%$ em peso do precursor vitrocerâmico LZSA e $67 \%$ de uma mistura de sais $\left(70 \% \mathrm{NaNO}_{3}\right.$ e $\left.30 \% \mathrm{Na}_{2} \mathrm{SO}_{4}\right)$ foram preparadas e tratadas termicamente em um forno mufla (Schaly, modelo 27-13, Campos Novos, Brasil; taxa de aquecimento de $10^{\circ} \mathrm{C}$ $\min ^{-1}$ ) a $450{ }^{\circ} \mathrm{C}$ e intervalos de $2,4,6,8$ e $10 \mathrm{~h}$. Uma mistura foi tratada a $600{ }^{\circ} \mathrm{C}$ por $6 \mathrm{~h}$.

Após os tratamentos térmicos, os pós foram lavados com água deionizada e solução de $\mathrm{HCl} 0,1 \mathrm{~mol} \mathrm{~L}^{-1}$, sendo ainda monitorados com condutivímetro, a fim de se obter condutividade elétrica semelhante à da água deionizada. Em seguida, cada composição foi seca em estufa de laboratório (Ceramic Instruments, Sassuolo, Itália; 110 $\pm 5^{\circ} \mathrm{C}, 12 \mathrm{~h}$ ). Cada composição foi compactada a cerca de $50 \mathrm{MPa}$ em matriz cilíndrica metálica por meio de prensa hidráulica de laboratório. Subsequentemente, um corpo de prova de cada composição foi submetido à determinação da curva de retração linear, por meio de um dilatômetro óptico (Expert System Solutions, Misura HSM ODHT 1400, Modena, Itália; taxa de aquecimento de $10{ }^{\circ} \mathrm{C} \mathrm{min}^{-1}$ ao ar).

Tendo como base os resultados obtidos das curvas de retração linear, a amostra tratada no intervalo de $6 \mathrm{~h}$ foi selecionada por apresentar a maior retração linear. As composições químicas dos pós tratados ionicamente e do pó não tratado foram determinadas em um espectrômetro de fluorescência de raios X (Philips PW 2400, Eindhoven, Holanda) e o percentual de lítio nas mesmas foi determinado por espectrometria de absorção atômica em chama Unicam (Solaar 969, Cambridge, Reino Unido).

A análise térmica diferencial (DTA) foi realizada em um termoanalisador (Netzsch STA 409EP, Selb, Alemanha; taxa de aquecimento de $10^{\circ} \mathrm{C} \mathrm{min}^{-1}$, em ar). As fases cristalinas formadas após os tratamentos térmicos foram identificadas por difratometria de raios $\mathrm{X}$ (Philips PW 3710, Eindhoven, Holanda), utilizando tubo de cobre (radiação
$\mathrm{Cu} \mathrm{K} \alpha$ ), em um intervalo de ângulo $2 \theta$ de $5^{\circ}$ a $60^{\circ}$, com passo de $0,02^{\circ}$. A microestrutura de compactos de pós tratados ionicamente e de pó não tratado foi avaliada por microscopia eletrônica de varredura (JEOL JSM -6390, Tóquio, Japão).

\section{RESULTADOS E DISCUSSÃO}

A Tabela 1 mostra a análise química dos pós do vidro LZSA tratados ionicamente e não tratado, para avaliação da eficácia do processo de troca iônica.

Tabela 1. Composição química de pós de vidro LZSA não tratado e tratados ionicamente a $450{ }^{\circ} \mathrm{C}$ por 2,6 e $8 \mathrm{~h}$ e a $600{ }^{\circ} \mathrm{C}$ por $6 \mathrm{~h}$

\begin{tabular}{cccccc}
\hline \multirow{2}{*}{$\begin{array}{c}\text { Óxidos } \\
\text { constituinte }\end{array}$} & $\begin{array}{c}\text { Pó não } \\
\text { tratado } \\
(\% \text { molar })\end{array}$ & $450{ }^{\circ} \mathrm{C} / 2 \mathrm{~h}$ & $450{ }^{\circ} \mathrm{C} / 6 \mathrm{~h}$ & $450{ }^{\circ} \mathrm{C} / 8 \mathrm{~h}$ & $600{ }^{\circ} \mathrm{C} / 6 \mathrm{~h}$ \\
\hline $\mathrm{SiO}_{2}$ & 62,07 & 62,61 & 62,50 & 62,55 & 58,82 \\
$\mathrm{Al}_{2} \mathrm{O}_{3}$ & 9,19 & 9,20 & 9,18 & 9,18 & 8,84 \\
$\mathrm{CaO}$ & 0,69 & 0,59 & 0,56 & 0,56 & 0,59 \\
$\mathrm{Fe}_{2} \mathrm{O}_{3}$ & 0,08 & 0,08 & 0,08 & 0,08 & 0,07 \\
$\mathrm{~K}_{2} \mathrm{O}$ & 0,34 & 0,36 & 0,35 & 0,36 & 0,25 \\
$\mathrm{MgO}$ & 0,31 & 0,38 & 0,30 & 0,30 & 0,30 \\
$\mathrm{MnO}$ & 0,05 & 0,05 & 0,06 & 0,06 & 0,05 \\
$\mathrm{Na}_{2} \mathbf{O}$ & $\mathbf{1 , 0 3}$ & $\mathbf{1 2 , 3 9}$ & $\mathbf{1 2 , 1 2}$ & $\mathbf{1 2 , 3 0}$ & $\mathbf{1 4 , 2 5}$ \\
$\mathrm{P}_{2} \mathrm{O}_{5}$ & 0,01 & 0,01 & 0,01 & 0,01 & 0,01 \\
$\mathrm{TiO}_{2}$ & 0,05 & 0,06 & 0,05 & 0,05 & 0,05 \\
$\mathbf{L i}_{2} \mathbf{O}$ & $\mathbf{1 8 , 1 0}$ & $\mathbf{6 , 3 2}$ & $\mathbf{6 , 6 6}$ & $\mathbf{6 , 6 0}$ & $\mathbf{8 , 9 1}$ \\
$\mathrm{BaO}^{n}$ & 0,17 & 0,13 & 0,15 & 0,13 & 0,12 \\
$\mathrm{ZnO}^{n}$ & 0,71 & 0,67 & 0,68 & 0,63 & 0,50 \\
$\mathrm{ZrO}_{2}$ & 7,19 & 7,16 & 7,31 & 7,18 & 7,25 \\
\hline
\end{tabular}

Conforme demonstrado na Tabela 1 , de fato ocorreu a troca efetiva, em base molar, do íon $\mathrm{Li}^{+1}$ pelo íon $\mathrm{Na}^{+1}$. Enquanto o percentual molar de $\mathrm{Na}^{+1}$ foi aumentado de 1 para $12 \%$, o percentual molar do íon $\mathrm{Li}^{+1}$ foi reduzido de 18 para $6 \%$, isto é, uma variação de cerca de 11 pontos percentuais. De fato, íons $\mathrm{Li}^{+1}$ podem ser mais eficientemente substituídos por íons $\mathrm{Na}^{+1}$ em vidros tratados com nitrato de sódio. ${ }^{8}$ Isto se deve ao elevado coeficiente de interdifusão entre os íons $\mathrm{Li}^{+1}-\mathrm{Na}^{+1}$, comparados, por exemplo, aos íons $\mathrm{Na}^{+1}-\mathrm{K}^{+1}$. Isto permite o tratamento térmico a temperaturas menores e em tempos mais curtos. A Tabela 1 mostra ainda que não houve alteração significativa nos valores dos percentuais dos íons $\mathrm{Na}^{+1}$ e $\mathrm{Li}^{+1}$ na temperatura de $450{ }^{\circ} \mathrm{C}$, apesar da mudança acentuada nos tempos de tratamento de troca iônica; por outro lado, a $600{ }^{\circ} \mathrm{C} / 6 \mathrm{~h}$ ocorreu acentuada redução do percentual molar da sílica, de 62,5 para $58,8 \%$ e aumento dos

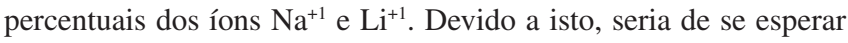
maior sinterabilidade da amostra tratada a $600{ }^{\circ} \mathrm{C} / 6 \mathrm{~h}$, devido ao maior teor de óxidos modificadores de rede. Entretanto, isto não foi verificado, como será mostrado adiante.

O comportamento térmico do pó tratado quimicamente a $450{ }^{\circ} \mathrm{C} / 6 \mathrm{~h}$ em comparação com o pó não tratado foi avaliado por DTA, como mostram as curvas da Figura 1. O tratamento termoquímico não influenciou a temperatura de transição vítrea, $\mathrm{T}_{\mathrm{g}}$, e a temperatura de cristalização, $T_{c}$, apesar do pico de cristalização ter sido mais bem definido na amostra não tratada quimicamente. Por outro lado, o intervalo de cristalização foi fortemente afetado pelo início do processo de fusão ocorrido nas amostras de pós tratados, como evidenciado nas Figuras 2 e 3. Além disso, o pico de cristalização 
do silicato de zircônio a $850{ }^{\circ} \mathrm{C}$, registrado por Montedo et al. ${ }^{7}$ não foi evidenciado na Figura 1.

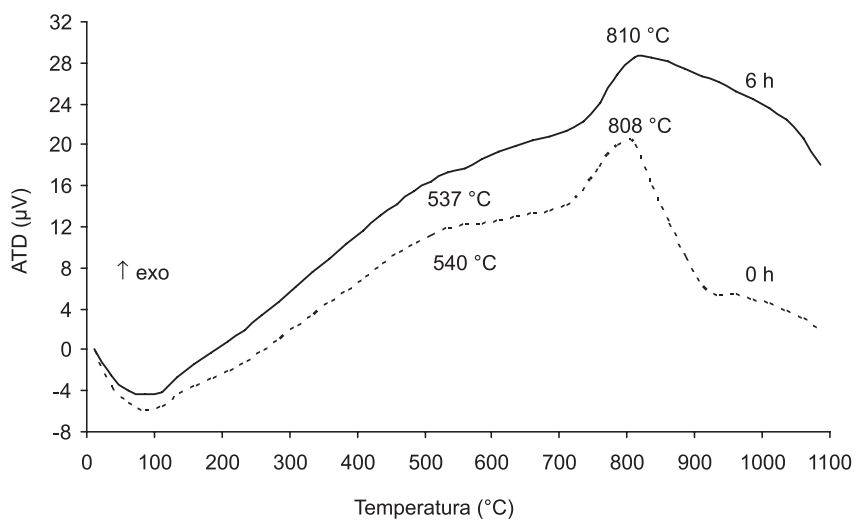

Figura 1. Termogramas (DTA) dos pós de vidro LZSA não tratado $(0 \mathrm{~h}) \mathrm{e}$ tratado ionicamente a $450{ }^{\circ} \mathrm{C} / 6 \mathrm{~h}$. Taxa de aquecimento de $10^{\circ} \mathrm{C} \mathrm{min}{ }^{-1}$ ao ar

Na Figura 2, que mostra a evolução de RL em função da temperatura, a curva de RL do vidro não tratado apresentou comportamento similar ao descrito por Montedo et al.. ${ }^{7}$ Todavia, as amostras submetidas ao tratamento de troca iônica $\left(450^{\circ} \mathrm{C} / 6 \mathrm{~h}\right.$ e $\left.600{ }^{\circ} \mathrm{C} / 6 \mathrm{~h}\right)$ apresentaram comportamento diferente da amostra não tratada, apesar de que, em ambos casos, a sinterização tenha ocorrido no mesmo

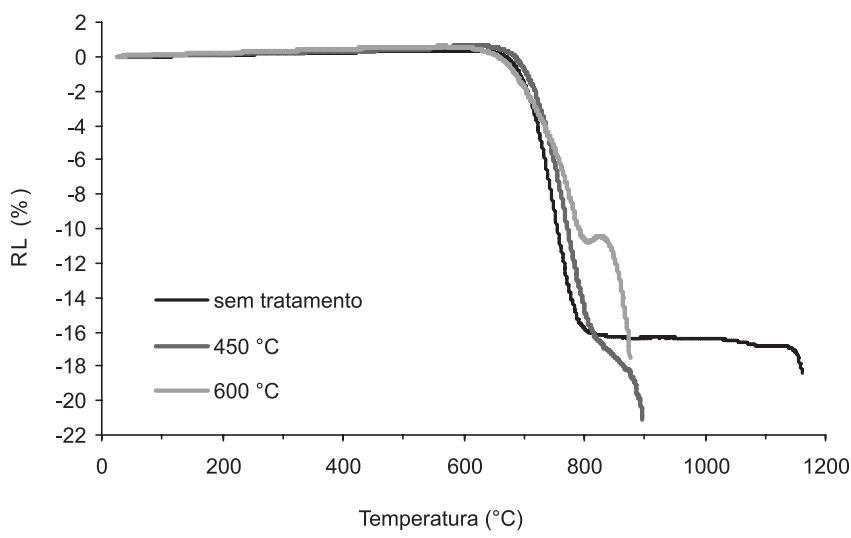

Figura 2. Curvas de RL em função da temperatura dos pós de vidro LZSA não tratado $(0 \mathrm{~h})$ e tratado ionicamente a $450{ }^{\circ} \mathrm{C} / 6 \mathrm{~h}$ e $600{ }^{\circ} \mathrm{C} / 6 \mathrm{~h}$

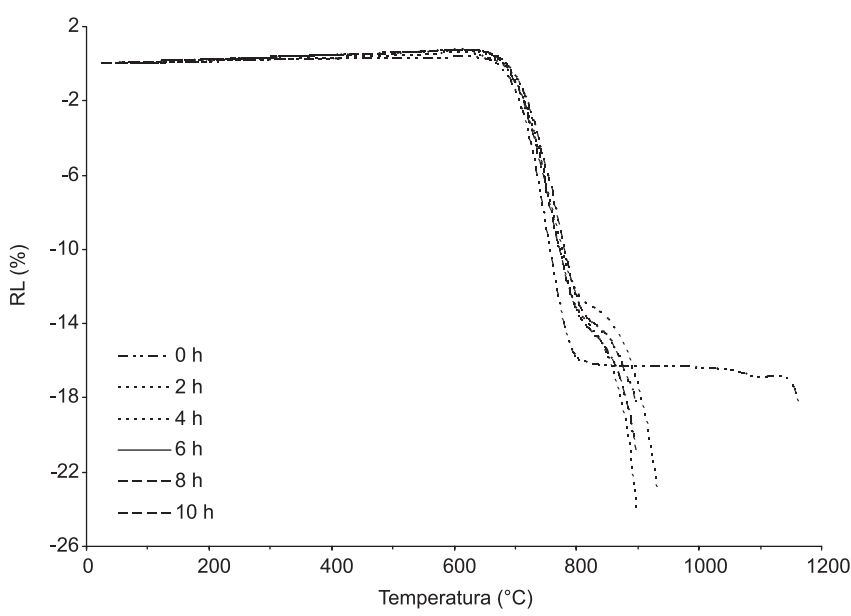

Figura 3. Curvas de RL em função da temperatura dos compactos de pós não tratado ionicamente $(0 \mathrm{~h})$ e tratados ionicamente em sais a $450{ }^{\circ} \mathrm{C}$ por $2,4,6,8$ e $10 \mathrm{~h}$, respectivamente. Taxa de aquecimento de $10^{\circ} \mathrm{C} \mathrm{min}^{-1}$ ao ar intervalo de temperatura, entre 680 e $800{ }^{\circ} \mathrm{C}$

Conforme relatado anteriormente para este sistema vitrocerâmico, ${ }^{7}$ a taxa de sinterização é reduzida drasticamente a cerca de $800{ }^{\circ} \mathrm{C}$, devido à cristalização da fase cristalina espodumênio- $\beta_{s s}$ (solução sólida de espodumênio- $\beta, \mathrm{Li}_{2} \mathrm{O} \cdot \mathrm{Al}_{2} \mathrm{O}_{3} \cdot 4-10 \mathrm{SiO}_{2}$ ), Figura 4. Ao contrário do vidro não tratado quimicamente, entretanto, os vidros tratados a $450{ }^{\circ} \mathrm{C} / 6 \mathrm{~h}$ e a $600{ }^{\circ} \mathrm{C} / 6 \mathrm{~h}$ não apresentaram estabilidade térmica, isto é, a RL permaneceu praticamente invariável com a temperatura, no intervalo entre a temperatura de cristalização e a temperatura de fusão. Além disso, o elevado aumento do percentual molar dos elementos modificadores de rede do vidro ( $\mathrm{Na}$ e Li) na amostra tratada a $600{ }^{\circ} \mathrm{C} / 6 \mathrm{~h}$ provocou, inclusive, expansão da amostra antes da fusão. Por outro lado, a cristalização das fases cristalinas espodumênio- $\beta_{s s}$ e silicato de zircônio reduz fortemente a taxa de sinterização. Entretanto, a substituição progressiva do íon $\mathrm{Li}^{+}$ pelo íon $\mathrm{Na}^{+}$reduziu a formação da fase cristalina espodumênio- $\beta_{s s}$. Como resultado, aumentou a quantidade de fase vítrea residual, rica em sódio, como pode ser visto na Figura 4.

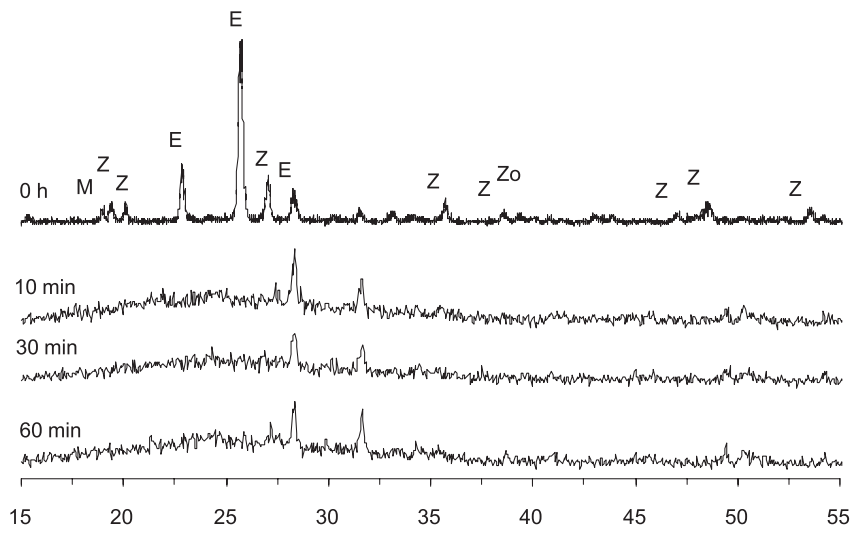

Figura 4. Difratogramas de compactos de pós não tratado $(0$ h) e tratados em sais a $450{ }^{\circ} \mathrm{C}$ por 10,30 e $60 \mathrm{~min} . \mathrm{Z}: \mathrm{ZrSiO}_{4} ; \mathrm{E}$ : espodumênio- $\beta_{s s} ; \mathrm{Zo}$ : $\mathrm{ZrO}_{2} ; \mathrm{M}: \mathrm{Li}_{2} \mathrm{SiO}_{3}$. Os compactos foram tratados termicamente $\left(800^{\circ} \mathrm{C} / 30\right.$ min) para sinterização e cristalização

Assim, a substituição do íon $\mathrm{Li}^{+}$pelo íon $\mathrm{Na}^{+}$reduziu a cristalização do material e, consequentemente, o intervalo de estabilidade dimensional $(\mathrm{dRL} / \mathrm{dT}=0)$. Isto deve ter reduzido a viscosidade do sistema, favorecendo a fundência do material a temperaturas inferiores àquela do vidro não tratado. Nesta amostra, ainda, a RL foi menor do que a esperada, por ter apresentado maior teor de elementos modificadores de rede.

A Figura 2 mostra que a inclinação da curva de RL x T (dRL/ dT) no intervalo de sinterização (entre 680 e $800{ }^{\circ} \mathrm{C}$ ) foi menor para a amostra tratada a $600{ }^{\circ} \mathrm{C} / 6 \mathrm{~h}$. Desta forma, a cristalização destes pós, que é do tipo superficial, ${ }^{7}$ foi antecipada, dificultando a evolução do processo de sinterização e o aumento da RL. De acordo com Navarro, ${ }^{13} \mathrm{o}$ aumento da temperatura ocasiona a implantação de íons e não a troca. Isso pode ser observado na Figura 3, que mostra as curvas de RL em função da temperatura dos compactos de pós tratados ionicamente em mistura salina a $450{ }^{\circ} \mathrm{C}$ a diferentes intervalos de tempo e de pó não tratado, onde o intervalo de RL foi menor que no tratamento realizado à temperatura mais baixa, indicando a implantação dos íons $\mathrm{Na}^{+}$. Esta implantação não produz o rompimento das ligações Si-O da rede cristalina e, portanto, a formação de tensões que densificam o pó.

Na Figura 3, em todas as amostras investigadas, a sinterização começou por volta de $670{ }^{\circ} \mathrm{C}$. O pó de vidro LZSA não tratado ionicamente atingiu sua máxima RL a cerca de $800^{\circ} \mathrm{C}$, conforme já observado em trabalho anterior. ${ }^{7}$ Esta temperatura coincide com a 
de máxima taxa de cristalização da fase cristalina espodumênio- $\beta_{s s}$ (Figura 1).

A Figura 5 mostra a temperatura de máxima taxa de sinterização, que ocorreu a temperaturas maiores para maiores tempos de tratamento químico dos pós. Isto se deve ao fato de que o íon $\mathrm{Li}^{+}$possui a capacidade de reduzir mais intensamente a viscosidade da composição durante o comportamento plástico-viscoso em relação ao íon $\mathrm{Na}^{+}$. Desta forma, a substituição de íons $\mathrm{Li}^{+}$por íons $\mathrm{Na}^{+}$deslocou a curva de sinterização (RL vs T), aumentando também a temperatura de máxima taxa de sinterização.

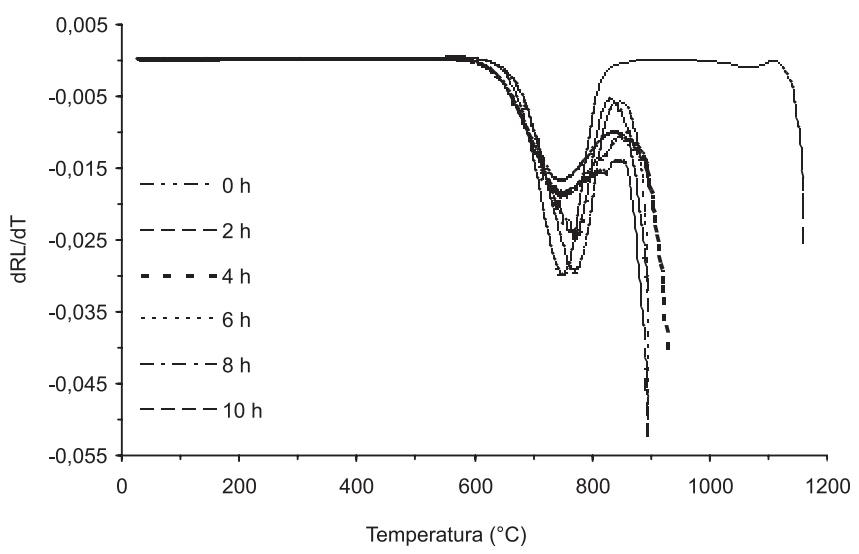

Figura 5. Curvas de derivada primeira da RL em função da temperatura dos compactos de pós não tratados $(0 \mathrm{~h})$ e tratados em sais a $450^{\circ} \mathrm{C}$ por $2,4,6$, 8 e $10 \mathrm{~h}$. Taxa de aquecimento de $10^{\circ} \mathrm{C} \mathrm{min}^{-1}$ ao ar

A cristalização neste sistema vitrocerâmico ocorre até cerca de $970{ }^{\circ} \mathrm{C}$, quando, então, se pode observar novamente um processo de aumento da RL até cerca de $1040{ }^{\circ} \mathrm{C}$. A partir desta temperatura, a RL praticamente não foi mais alterada até a temperatura de fusão, a cerca de $1140{ }^{\circ} \mathrm{C}$. Os pós tratados ionicamente, por outro lado, apresentaram um comportamento um pouco diferente. Como pode ser visto na Figura 3, aparentemente, o início do processo de cristalização foi um pouco retardado, iniciando a cerca de $810^{\circ} \mathrm{C}$, provavelmente devido à substituição parcial do íon $\mathrm{Li}^{+}$pelo íon $\mathrm{Na}^{+}$. Entretanto, ao contrário do pó não tratado ionicamente, os pós tratados apresentaram contínua redução da RL, devido ao aumento do teor de elementos modificadores de rede na superfície dos pós, especificamente sódio (Na) e lítio (Li). Estes elementos promovem o rompimento das ligações $\mathrm{Si}-\mathrm{O}$ da rede vítrea, que são restabelecidas em ligações $\mathrm{Na}-\mathrm{O}$ e Li-O na superfície dos pós. Apesar disto não ter sido comprovado por meio de espectro de infravermelho ou Raman, as amostras foram adequadamente lavadas após ataque químico e a análise química, realizada posteriormente, indicou a alteração na composição química, conforme a Tabela 1. Isto indica a incorporação do íon $\mathrm{Na}^{+}$na rede cristalina, entretanto, não promoveu modificação apreciável na $\mathrm{T}_{\mathrm{g}}$, que é uma propriedade volumétrica, mas sim na sinterabilidade do vidro, que é sensivelmente alterada pelas características superficiais do pó. Neste caso, a amostra tratada a $450{ }^{\circ} \mathrm{C} / 6 \mathrm{~h}$ foi a que apresentou maior RL. Os tratamentos térmicos para troca iônica, conforme evidenciado na Figura 1, afetaram fortemente a sinterabilidade dos compactos de pós preparados ionicamente.

Os compactos obtidos a partir dos pós tratados ionicamente apresentaram maior densificação em comparação àqueles não tratados, como pode ser observado na Figura 6. A microestrutura do compacto obtido a partir do pó tratado ionicamente a $450{ }^{\circ} \mathrm{C} / 6$ h, Figura 6b, é mais densa e com maior esfericidade da porosidade residual em relação ao pó não tratado ionicamente, Figura $6 \mathrm{a}$, indicando que o tratamento superficial prévio dos pós de fato aumentou sua sinterabilidade. Claramente, observa-se maior evolução microestrutural na amostra tratada quimicamente em direção a um corpo menos poroso.
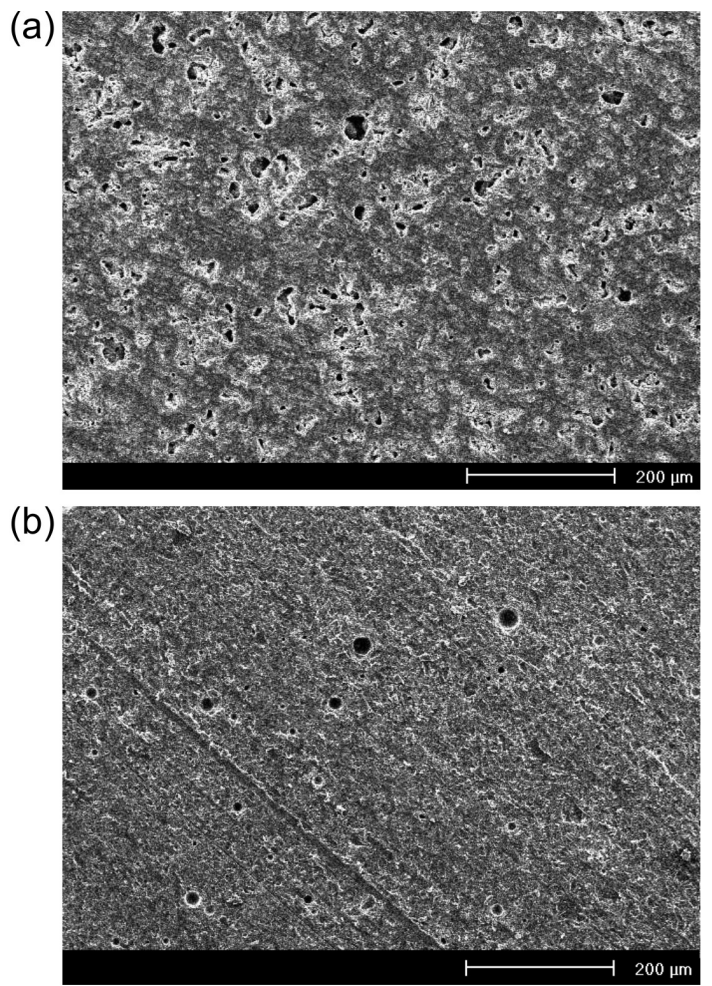

Figura 6. Micrografias (MEV) referentes às amostras de pós (a) não tratado (vitrocerâmico LZSA) e (b) tratado com sais de sódio a $450^{\circ} \mathrm{C} / 6$ h. Os compactos de ambos os pós foram tratados termicamente $\left(850^{\circ} \mathrm{C} / 30 \mathrm{~min}\right)$ para sinterização e cristalização. Aumento: $100 \mathrm{X}$

\section{CONCLUSÃO}

Alterações composicionais de partículas irregulares de pó do precursor vitrocerâmico do sistema $\mathrm{LZSA}\left(\mathrm{Li}_{2} \mathrm{O}-\mathrm{ZrO}_{2}-\mathrm{SiO}_{2}-\mathrm{Al}_{2} \mathrm{O}_{3}\right)$, decorrente de processo de troca iônica com sais de sódio na superfície destas partículas, foram obtidas com sucesso mediante tratamentos térmicos a $450{ }^{\circ} \mathrm{C}$ por períodos de 2 a $8 \mathrm{~h}$. A troca iônica foi efetiva, comprovada por análise química, e não modificou significativamente as propriedades térmicas do vidro. Entretanto, a sinterabilidade dos pós foi sensivelmente modificada. Como consequência, os compactos obtidos a partir do pó tratado ionicamente apresentaram maior densificação e excelente esfericidade dos poros residuais, que foram caracterizados por análise microestrutural, em comparação com o pó não tratado.

\section{AGRADECIMENTOS}

À CAPES e ao CNPq pelo suporte financeiro destinado à realização deste trabalho.

\section{REFERÊNCIAS}

1. Banerjee, R.; Bose, N. R. Em Fibre Reinforced Glass/Glass-Ceramic Matrix Composites; Low, I. M., ed.; Woodhead Publishing Limited: Cambridge, 2006, part 1.

2. Taylor, G. F.; US pat. 1,896,854 1933.

3. Chan, H. M.; Annu. Rev. Mater. Sci. 1997, 27, 249.

4. Winter, W.; Fourth Euro Ceramics 1997, 2, 457.

5. Scherer, G. W.; Bachman, D. L.; J. Am. Ceram. Soc. 1977, 60, 239. 
6. Kim, K. D.; Khalil, T.; J. Non-Cryst. Solids 1996, 195, 218

7. Montedo, O. R. K.; Floriano, F. J.; Oliveira Filho, J. de; Angioleto, E.; Bernardin, A. M.; Mater. Res. 2009, 12, 197.

8. Gy, C.; Mater. Sci. Eng., B 2008, 149, 159.

9. Salavcova, L.; Spirkova, J.; Mika, M.; Mackova, A.; Oswald, J.; Langrova, A.; Vacik, J.; Opt. Mater. 2007, 29, 753.

10. Blet, V.; Rudloff, D.; Berne, P.; Jollivet, P.; Schweich, D.; Chem. Eng. Sci. 2002, 57, 3427.
11. Di Nunzio, S.; Brovarone, C. V.; Spriano, S.; Milanese, D.; Verné, E.; Bergo, V.; Maina, G.; Spinelli, P.; J. Eur. Ceram. Soc. 2004, 24, 2935.

12. Kingery, W. D.; Bowen, H. K.; Uhlmann, D. R.; Introduction to Ceramics, $2^{\text {nd }}$ ed., John Wiley \& Sons: New York, 1976.

13. Navarro, J. M. F.; El vidrio, $3^{\mathrm{a}}$ ed., Consejo Superior de Investigaciones Científicas: Madrid, 2003. 